\title{
Difference in the Mode of Acute Cold-Induced Hypothermia between Rat and Hamster
}

\author{
Katsuo Uchida, Izumi Shibuya, and Katsuhiko DoI \\ Department of Physiology, Yamagata University School of Medicine, \\ Yamagata, 990-23 Japan
}

\begin{abstract}
The present work was undertaken to elucidate the underlying causative factors limiting survival in hypothermic rats (non-hibernator) and hamsters (hibernator). A variety of physiological and biochemical parameters were measured for 28 male Wistar rats (205-286 g) and 26 male golden hamsters $(85-118 \mathrm{~g})$ before and during induction of hypothermia to colonic temperature $(T \mathrm{co})$ of $18^{\circ} \mathrm{C}$. With progressive decreases in $T \mathrm{co}$, parallel falls in $\dot{V}_{\mathrm{O}_{2}}, \dot{V}_{\mathrm{CO}_{2}}$, and heart rate were observed. In rats, plasma $\mathrm{pH}\left(\mathrm{pH}_{\mathrm{p}}\right)$ in arterial blood was significantly lowered from 7.453 at $T$ co of $38^{\circ} \mathrm{C}$ to 7.327 at $T$ co of $18^{\circ} \mathrm{C}(p<0.001)$. From the observations of increased arterial $P_{\mathrm{CO}_{2}}$ and bound $\mathrm{CO}_{2}$ (bicarbonate ion) concentration, together with the unchanged blood lactate, respiratory acidosis caused by hypoventilation was suggested to be responsible for the decrease in $\mathrm{pH}_{\mathrm{p}}$. In contrast to rats, in hamsters $\mathrm{pH}_{\mathrm{p}}$. was almost unchanged during the induction of hypothermia, while nearly complete depletion of blood glucose $(-84.6 \%)$ and liver glycogen $(-99.5 \%)$ were observed when $T$ co of $38^{\circ} \mathrm{C}$ was lowered to $18^{\circ} \mathrm{C}$. It is concluded that the decrease in $\mathrm{pH}_{\mathrm{p}}$ is a limiting factor for rats to survive the deep hypothermia at $T$ co of $18^{\circ} \mathrm{C}$ and the exhaustion of carbohydrates as an energy supply for hamsters.
\end{abstract}

Key words: hypothermia, acidosis, blood gases, carbohydrates, free fatty acids.

Under severe cold, when heat loss surpasses heat production progressive hypothermia will lead to death of homeothermic animals unless properly rectified. Systematic studies of the physiological changes durig hypothermia are necessary to identify the mechanisms for the failure in homeostasis as well as the inability to recover from it. Although many studies have been made on the underlying potential factors limiting survival in the hypothermic state, the cause of death due to acute hypothermia is controversial and still not completely understood (PrEwITT et al.,

Received for publication December 15, 1986 
1972; MusaCCHIA and JACOBS, 1973; WANG, 1978).

It is reasonable to assume that factors other than the direct effect of temperature must play a role in limiting the survival in hypothermia. One of the important factors to be considered in studying the physiology of hypothermia is the change in the gas transport system which affects the supply of $\mathrm{O}_{2}$ to and the removal of $\mathrm{CO}_{2}$ from tissues. The adequateness of the gas transport system during hypothermia can be evaluated by correlating $P_{\mathrm{CO}_{2}}, P_{\mathrm{O}_{2}}$, and $\mathrm{pH}$ in blood with the oxygen uptake. These parameters are precisely regulated to meet the metabolic demands, as evidenced by the constancy of the ventilatory function, acid-base balance, and energy substrate metabolism. In particular, alterations in plasma $\mathrm{pH}$ are important features of the physiological adjustments accompanying the bodytemperature change in animals (RAHN et al., 1975). Plasma pH and blood gases in hypothermia have been extensively studied for hibernators (LYMAN and HASTINGS, 1951; Kent and PeirCE II, 1967; VolKert and MusaCChIA, 1970). The regulatory mechanisms involved in the acid-base status are not well assessed in hypothermia. WANG and PETER (1977) reported for rats that hypothermia induced by the cold exposure with a $\mathrm{He}-\mathrm{O}_{2}$ mixed gas was not due to any form of respiratory failure, but to a metabolic one. However, in the present work, we have observed marked changes in the regulation of respiration in hypothermic rats.

Another important factor causing the failure in heat balance is a metabolic response to hypothermia. Blood glucose and free fatty acids are known as the major fuels for shivering thermogenesis, the primary means of heat production in acute cold exposure in rats (Dor et al., 1979). Changes in energy substrates for heat production have been investigated for hypothermic homeotherms (FUHRMAN and Crismon, 1947; Popovic, 1960; Depocas, 1962). However, no measurements have been reported on the simultaneous variations in the gas exchange and energy substrates metabolism during hypothermia. In the present work, we have measured plasma $\mathrm{pH}$, blood gases, and energy substrates at various stages of hypothermia in rats (non-hibernator) and hamsters (hibernator). Since hypothermia in rats has not been closely compared with that in hamsters, either in duration and depth of hypothermia or in the limiting factors, it is unknown whether similar failures in heat balance occur in both.

\section{MATERIALS AND METHODS}

Experimental animals. Male Wistar rats weighing 205-286 g $(235 \pm 4.0 \mathrm{~g}$; $n=28)$ and male golden hamsters weighing $85-118 \mathrm{~g}(100 \pm 1.7 \mathrm{~g} ; n=26)$ were used in this study (mean \pm standard error (S.E.); and the number of animals in parentheses). Animals were housed at a constant temperature of $23 \pm 2^{\circ} \mathrm{C}$ under controlled artificial illumination of a 14-h light and 10-h dark cycle, and fed on a laboratory rat chow (Oriental MF, Oriental Yeasts, Tokyo) and water ad libitum. All animals were used in the fed state, and each experiment was started at 9 a.m.

Induction of hypothermia. Unanesthetized animals were fur-clipped and gent- 
ly restrained in Bollman cages $(5 \mathrm{~cm}$ in diameter and $15 \mathrm{~cm}$ in length for rats; $3 \mathrm{~cm}$ in diameter and $10 \mathrm{~cm}$ in length for hamsters), which were made with a slight modification of the original one (Bollman, 1948). The restraint by the cages allowed animals' small movements, but did not allow a change of body position. The cages proved a great help in stabilizing a thermistor probe (Takara Kogyo, Tokyo) for measuring the colonic temperature (Tco). The probe was placed at 4 $5 \mathrm{~cm}$ into the colon and secured to the tail with tape. The cage was kept in a hermetically closed metabolic box, a brass box of $9 \mathrm{~cm}$ in length, $23 \mathrm{~cm}$ in width and $9 \mathrm{~cm}$ in height. The animal was kept inside the metabolic box for $30 \mathrm{~min}$ at room temperature; then the box was immersed in an ice water-bath of $0^{\circ} \mathrm{C}$ and the animal was exposed to cold. During the cold exposure, Tco and the temperature in the box (Ta) were continuously measured using thermistor thermometers (Takara Kogyo, Tokyo). It took about $30 \mathrm{~min}$ for the equilibration of the $T$ a to ca. $2{ }^{\circ} \mathrm{C}$. The induction of hypothermia was achieved by using normal air. The flow rate of air through the system was set at $300 \mathrm{ml} / \mathrm{min}$, which was equivalent to that reported by ANDERSON et al. (1971). The flow rate was thought to be sufficient for the $\mathrm{O}_{2}$ consumption of rats and hamsters, because the oxygen concentration in air was five times as high as the measured maximum $\mathrm{O}_{2}$ consumptions (cf. Table 1). In order to maintain the same condition for heat convection, the same flow rate was set for both animals. The cold exposure was stopped at $T$ co of 30 and $18^{\circ} \mathrm{C}$ for rats and at $18^{\circ} \mathrm{C}$ for hamsters, and physiological and biochemical parameters were measured.

Measurements of $\dot{V}_{\mathrm{O}_{2}}, \dot{V}_{\mathrm{CO}_{2}}$, and $R Q$. Expired gas mixture sampled from an outflow tube of the metabolic box was analyzed for its $\mathrm{O}_{2}$ and $\mathrm{CO}_{2}$ concentrations by using an automatic gas analyzer (San-ei, 1H26). The sampling rate of the analyzer was $200 \mathrm{ml} / \mathrm{min}$. The accuracy of the analyzer was confirmed to be $\pm 0.1 \%$ $\mathrm{O}_{2}$ and $\mathrm{CO}_{2}$ within the ranges of $8-70 \% \mathrm{O}_{2}$ and $0-10 \% \mathrm{CO}_{2}$. The gas concentrations of standard gases used for the calibration of the analyzer were accurately determined with a Scholander gas analyzer (Tatebe Seishudo, Tokyo). The oxygen uptake $\left(\dot{V}_{\mathrm{O}_{2}}\right)$, carbon dioxide output $\left(\dot{V}_{\mathrm{CO}_{2}}\right)$, and respiratory quotient (RQ) were calculated from the flow rate of air and the change in $\mathrm{O}_{2}$ and $\mathrm{CO}_{2}$ concentrations in the metabolic box:

$$
\begin{aligned}
\dot{V}_{\mathrm{O}_{2}}\left(\dot{V}_{\mathrm{CO}_{2}}\right) & =\frac{\text { Flow rate }(\mathrm{ml} / \mathrm{min}) \times 60}{\text { Body weight }(\mathrm{g})} \cdot \frac{\Delta \% \mathrm{O}_{2}\left(\Delta \% \mathrm{CO}_{2}\right)}{100} \quad(\mathrm{ml} /(\mathrm{g} \cdot \mathrm{h})), \\
\mathrm{RQ} & =\dot{V}_{\mathrm{CO}_{2}} / \dot{V}_{\mathrm{O}_{2}} .
\end{aligned}
$$

The $\dot{V}_{\mathrm{O}_{2}}$ and $\dot{V}_{\mathrm{CO}_{2}}$ values were then converted to those in the standard conditions of temperature and pressure.

Heart rate. Heart rate (HR) was counted from the time intervals between adjacent R-waves of electrocardiograms (ECG). The ECG was recorded during the induction of hypothermia by inserting pin electrodes subcutaneously at positions over the right clavicle and on the lower border of the left thorax by referring to ANDERSON et al. (1971). 
Blood and tissue samplings. When Tco had dropped to 30 or $18^{\circ} \mathrm{C}$, animals were taken out of the box. Then, they were subjected to laparotomy under a light anesthesia with ether and $1-2 \mathrm{ml}$ of blood was drawn anaerobically from the abdominal aorta and the vena cava into heparinized plastic syringes. Subsequently the liver was excised, placed in sealed vials and immediately frozen in a freezer. These samples were stored frozen for later analyses of glycogen content in tissue.

Plasma was obtained by an anaerobic centrifugation of blood at $640 \mathrm{~g}$ for $10 \mathrm{~min}$ under liquid paraffin in a cone-shaped cuvette in order to prevent air contamination of the blood sample. Blood was deproteinized with $\mathrm{Ba}(\mathrm{OH})_{2}$ and $\mathrm{ZnSO}_{4}$ solutions for the measurements of glucose and lactic acid. For the extraction of free fatty acids, blood was treated with chloroform and a phosphate buffer solution.

Determination of plasma $\mathrm{pH}$ and blood gases. Immediately after the blood samplings, arterial and venous $\mathrm{pH}, P_{\mathrm{CO}_{2}}$, and $P_{\mathrm{O}_{2}}$ were measured with ordinary electrodes (I-L Meter, 213) calibrated with two standard phosphate buffer solutions and two standard gases. The $\mathrm{O}_{2}, \mathrm{CO}_{2}$, and $\mathrm{pH}$ electrodes were maintained at the same temperature as $T$ co of each animal from which the blood sample was taken. The errors in $\mathrm{pH}$ and blood gases due to a small temperature variation were corrected by using the temperature coefficients of RosENTHAL (1948) and SeVEringhaus (1964). Since the $\mathrm{pH}$ measured in the present work was that in plasma, the value will be referred to as $\mathrm{pH}_{\mathrm{p}}$, with the subscript denoting plasma. Total $\mathrm{CO}_{2}$ content in plasma $\left(C_{\mathrm{p}}\right)$ was measured with a manometric apparatus (Kayagaki Irikakogyo, Tokyo) according to NATELSON (1951). Bound $\mathrm{CO}_{2}$ concentration in plasma, $\left(\overline{\mathrm{CO}}_{2}\right)_{\mathrm{p}}$, most of which is the $\mathrm{HCO}_{3}{ }^{-}$concentration, was calculated from the observed $C_{\mathrm{p}}$ values by subtracting the physically dissolved $\mathrm{CO}_{2}$ :

$$
\left(\overline{\mathrm{CO}}_{2}\right)_{\mathrm{p}}=C_{\mathrm{p}}-\alpha_{\mathrm{p}} \cdot P_{\mathrm{CO}_{2}}
$$

where $\alpha_{\mathrm{p}}$ is the $\mathrm{CO}_{2}$ solubility coefficient in plasma. The temperature dependence of $\alpha_{\mathrm{p}}$ in $\mathrm{mm} /$ Torr was formulated from the table of SEVERINGHAUs (1964) as

$$
\log \alpha_{\mathrm{p}}=-1.045-0.01647 \cdot T+1.032 \times 10^{-4} \cdot T^{2},
$$

where $T$ represents a temperature in degrees centigrade $\left({ }^{\circ} \mathrm{C}\right)$. Hematocrit was determined in a heparinized capillary tube after centrifuging at $5,300 \mathrm{~g}$ for $8 \mathrm{~min}$ (McGovern et al., 1955).

All measurements were carried out duplicately.

Assay of substrates for heat production. Blood glucose was measured according to the anthrone reagent method (RoE, 1955). Lactic acid (LA) and free fatty acids (FFA) were determined from the colorimetric methods of BARKER and Summerson (1941) and ITAYA and UI (1965), respectively. A 1-ml-aliquot of filtrate was assayed for glycogen by using the method of CARroll et al. (1956). The blank and standard samples were simultaneously analyzed with blood sample. The standard reagents were glucose, lithium lactate, and palmitic acid for both glucose and glycogen, LA, and FFA, respectively. 


\section{RESULTS}

Time courses of Tco, $\dot{V}_{\mathrm{O}_{2}}, \dot{V}_{\mathrm{CO}_{2}}$, and $H R$

Simultaneous recordings were made with $T \mathrm{co}, \dot{V}_{\mathrm{O}_{2}}, \dot{V}_{\mathrm{CO}_{2}}$, and $\mathrm{HR}$ during

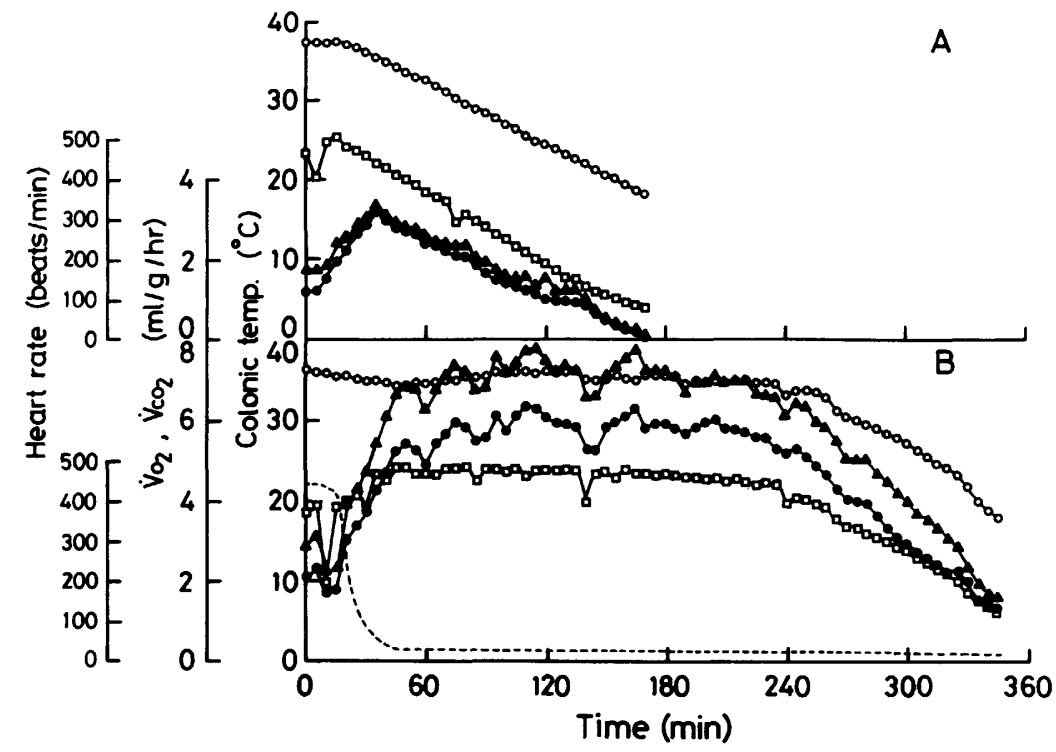

Fig. 1. A typical example of the time courses of $T \mathrm{co}(\mathrm{O}), \dot{V}_{\mathrm{O}_{2}}(\mathbf{\Delta}), \dot{V}_{\mathrm{CO}_{2}}(\bullet)$, and $\mathrm{HR}$ $(\square)$ in rats (A) and hamsters (B) during cold exposure. The broken line indicates the temperature in the metabolic box.

Table 1. Comparison of the time courses of $T \mathrm{co}, \dot{V}_{\mathrm{O}_{2}}, \dot{V}_{\mathrm{CO}_{2}}$, and $\mathrm{HR}$ during cold exposure and the maximum values of $\dot{V}_{\mathrm{O}_{2}}$, $\dot{V}_{\mathrm{CO}_{2}}$, and $\mathrm{HR}$ between rats and hamsters.

\begin{tabular}{lrrrr}
\hline & \multicolumn{1}{c}{ Rat } & Hamster & \\
\hline$t(30)$ & $(\mathrm{min})$ & $85 \pm 6.5$ & $307 \pm 28.8$ & $p<0.001$ \\
$t(18)$ & $(\mathrm{min})$ & $183 \pm 8.6$ & $388 \pm 29.4$ & $p<0.001$ \\
$t\left(\dot{V}_{\mathrm{O}_{2}}\right)$ & $(\mathrm{min})$ & $39 \pm 5.2$ & $127 \pm 9.7$ & $p<0.001$ \\
$t\left(\dot{V}_{\mathrm{CO}_{2}}\right)$ & $(\min )$ & $38 \pm 5.0$ & $124 \pm 10.3$ & $p<0.001$ \\
$t(\mathrm{HR})$ & $(\mathrm{min})$ & $15 \pm 1.4$ & $94 \pm 9.6$ & $p<0.001$ \\
$\dot{V}_{\mathrm{O}_{2} \max }$ & $(\mathrm{ml} /(\mathrm{g} \cdot \mathrm{hr}))$ & $3.5 \pm 0.09$ & $7.4 \pm 0.17$ & $p<0.001$ \\
$\dot{V}_{\mathrm{CO}_{2 \max }}$ & $(\mathrm{ml} /(\mathrm{g} \cdot \mathrm{hr}))$ & $3.0 \pm 0.15$ & $5.9 \pm 0.19$ & $p<0.001$ \\
$\mathrm{HR}_{\max }$ & $($ beats $/ \mathrm{min})$ & $510 \pm 4$ & $500 \pm 7$ & $\mathrm{NS}$ \\
\hline
\end{tabular}

Mean \pm S.E. values are shown in the table. $t(30)$ and $t(18)$ are induction time to hypothermia at $T \mathrm{co}$ of 30 and $18^{\circ} \mathrm{C}$, respectively. $t\left(\dot{V}_{\mathrm{O}_{2}}\right), t\left(\dot{V}_{\mathrm{CO}_{2}}\right)$, and $t(\mathrm{HR})$ are the coldexposing times to reach the maximum values of $\dot{V}_{\mathrm{O}_{2}}, \dot{V}_{\mathrm{CO}_{2}}$, and $\mathrm{HR}$, respectively. $\dot{V}_{\mathrm{O}_{2} \max }$, $\dot{V}_{\mathrm{CO}_{2} \max }$, and $\mathrm{HR}_{\max }$ are the respective maximum values. 
Table 2. Mean and S.E. values of arterial $\mathrm{pH}_{\mathrm{p}}, P_{\mathrm{CO}_{2}}, P_{\mathrm{O}_{2}},\left(\overline{\mathrm{CO}_{2}}\right)_{\mathrm{p}}, \mathrm{p} K^{\prime}$, and

$\mathrm{Ht}$ in normo- and hypothermic rats and hamsters.

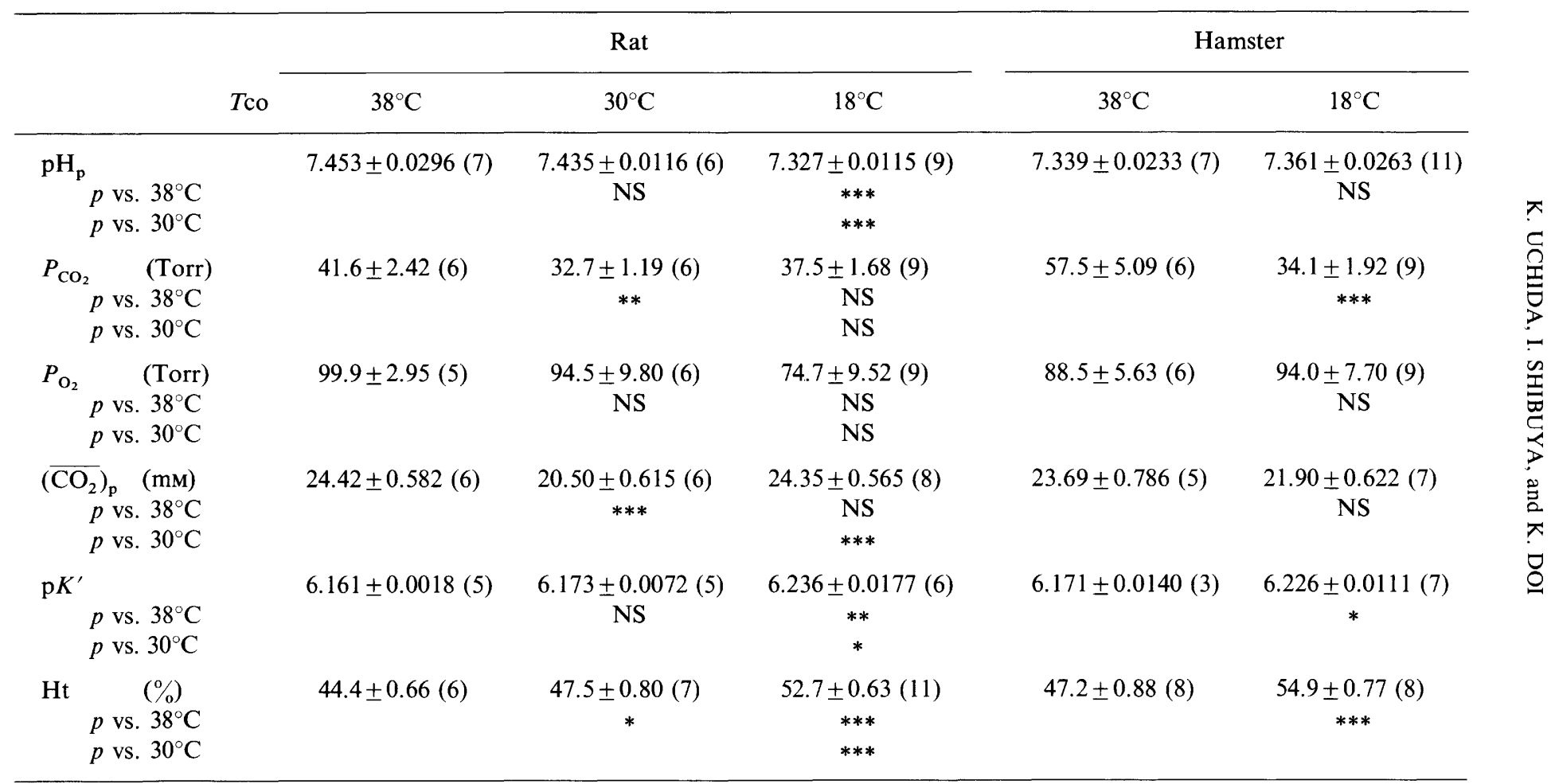

$*, * *, * * *$, and NS represent $p<0.05,<0.01,<0.001$, and non-significance, respectively, by Student's $t$-test. Numbers in parentheses indicate the experimental number. 


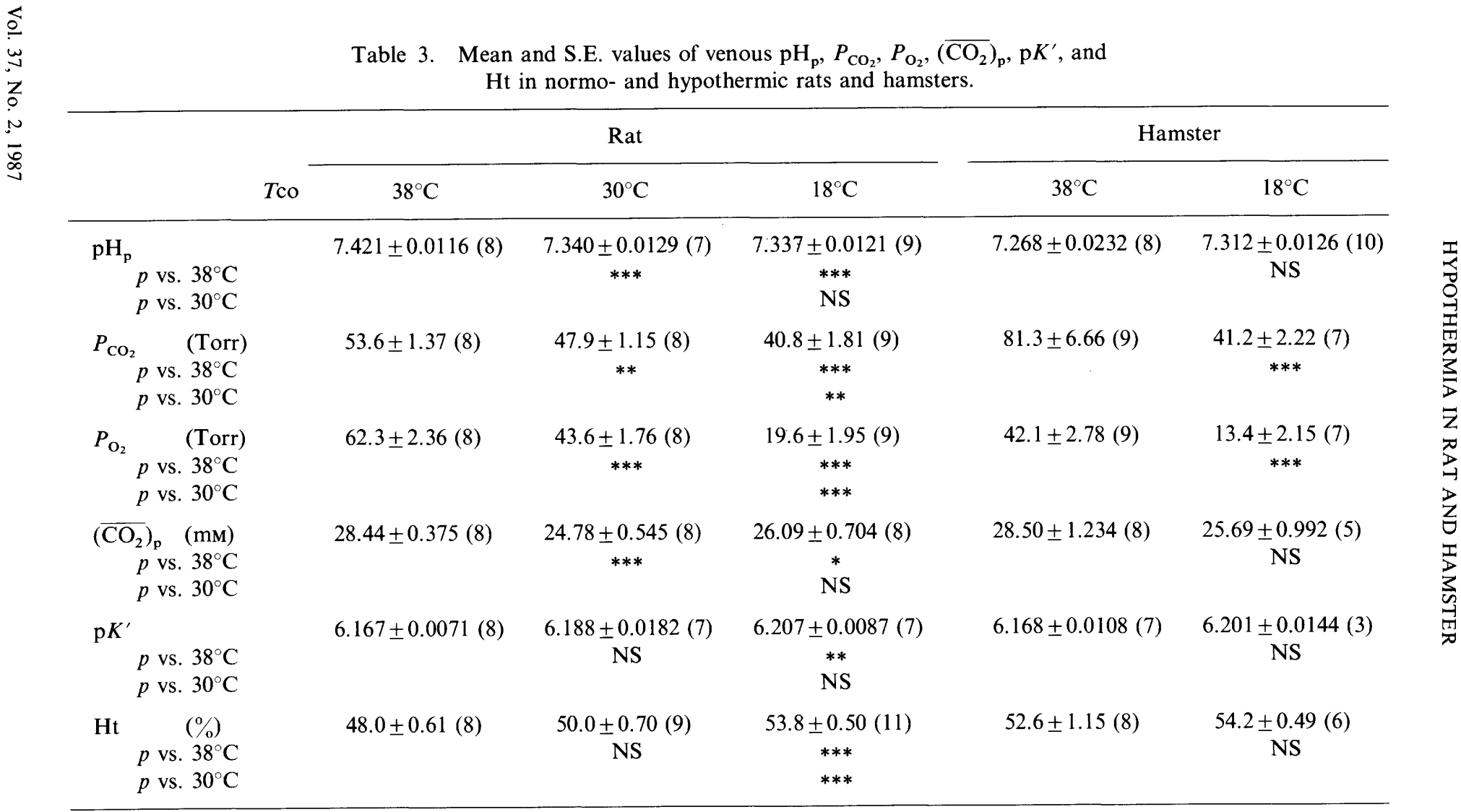

Legends are the same as in Table 2. 
exposure to cold. Figure 1 shows a typical record for the changes of $T \mathrm{co}, \dot{V}_{\mathrm{O}_{2}}, \dot{V}_{\mathrm{CO}_{2}}$, and HR for a rat (\#40) (panel A) and a hamster (\#11) (panel B) during cold exposure. The mean \pm S.E. of the induction times to hypothermia at $T$ co of 18 and $30^{\circ} \mathrm{C}$ are shown in Table 1 , together with those of the times when the $\dot{V}_{\mathrm{O}_{2}}, \dot{V}_{\mathrm{CO}_{2}}$, and $\mathrm{HR}$ reached their maximum values. The mean \pm S.E. of the maximum $\dot{V}_{\mathrm{O}_{2}}, \dot{V}_{\mathrm{CO}_{2}}$, and HR are also shown in the table. As shown in Table 1, the induction time of hypothermia at $T$ co of 18 and $30^{\circ} \mathrm{C}$ by using the restraint-cold method was significantly longer for hamsters than for rats $(p<0.001)$. However, the induction time from 30 to $18^{\circ} \mathrm{C}$ for hamsters $(81 \mathrm{~min})$ was comparable with that for rats (98 min). Rats did not show a constant level of $\dot{V}_{\mathrm{O}_{2}}$, while hamsters maintained a high constant level of $\dot{V}_{\mathrm{O}_{2}}$ over the period of about $150 \mathrm{~min}$. During this period, small variations in $\dot{V}_{\mathrm{O}_{2}}$ were exhibited. The $\dot{V}_{\mathrm{O}_{2}}$ decreased progressively from the peak value of 3.5 to $0.3 \mathrm{ml} /(\mathrm{g} \cdot \mathrm{h})$ for rats and from 7.4 to $1.5 \mathrm{ml} /(\mathrm{g} \cdot \mathrm{h})$ for hamsters. The $\dot{V}_{\mathrm{O}_{2}}$ per unit mass was significantly larger in hamsters than in rats. The $\dot{V}_{\mathrm{CO}_{2}}$ changed with $T$ co in essentially the same manner as the $\dot{V}_{\mathrm{O}_{2}}$ (Fig. 1); therefore RQ was nearly constant $(0.74-0.85)$ during the induction of hypothermia for both the animals. Hamsters maintained much longer stable states of $T \mathrm{co}, \dot{V}_{\mathrm{O}_{2}}$, $\dot{V}_{\mathrm{CO}_{2}}$, and $\mathrm{HR}$ than rats $(p<0.001)$, but once the failure in the maintenance of the stable states occurred, the decreases in Tco, $\dot{V}_{\mathrm{O}_{2}}, \dot{V}_{\mathrm{CO}_{2}}$, and HR were faster than those in rats. The $\mathrm{CO}_{2}$ concentration in the metabolic box was calculated by dividing the $\dot{V}_{\mathrm{CO}_{2}}$ by the flow rate of air and showed the range of 1 to $3 \%$.

$p \mathrm{H}_{\mathrm{p}}, \mathrm{P}_{\mathrm{CO}_{2}}, P_{\mathrm{O}_{2}}$, and $\left(\overline{\mathrm{CO}}_{2}\right)_{\mathrm{p}}$

Table 2 represents the arterial $\mathrm{pH}_{\mathrm{p}}$, blood gases, and hematocrit $(\mathrm{Ht})$ data for both rats and hamsters in normo- and hypothermia. Rats kept the normothermic $\mathrm{pH}_{\mathrm{p}}$ level at $T \mathrm{co}$ of $30^{\circ} \mathrm{C}$ and the value significantly decreased between 30 and $18^{\circ} \mathrm{C}$ $(p<0.001)$. In hamsters, $\mathrm{pH}_{\mathrm{p}}$ remained almost unchanged on going from 38 to $18^{\circ} \mathrm{C}$. The $\mathrm{Pa}_{\mathrm{CO}_{2}}$ in rats decreased between 38 and $30^{\circ} \mathrm{C}(p<0.01)$ and increased again between 30 and $18^{\circ} \mathrm{C}$, though the change was not statistically significant. The $\mathrm{Pa}_{\mathrm{CO}_{2}}$ in hamsters decreased significantly between 38 and $18^{\circ} \mathrm{C}(p<0.001)$. The $\mathrm{Pa}_{\mathrm{O}_{2}}$ in rats showed a declining tendency with lowering $T \mathrm{co}$, while the value in hamsters showed a slight increase between 38 and $18^{\circ} \mathrm{C}$. The $\left(\overline{\mathrm{CO}}_{2}\right)_{\mathrm{p}}$ of rats declined from 38 to $30^{\circ} \mathrm{C}(p<0.001)$ and increased again from 30 to $18^{\circ} \mathrm{C}(p<0.001)$. The apparent first dissociation constant of carbonic acid, $\mathrm{p} K^{\prime}$ (SIGGAARD-ANDERSEN, 1962) was calculated from the Henderson-Hasselbalch equation (Eq. (2)) by using the observed $\mathrm{pH}_{\mathrm{p}}, P_{\mathrm{CO}_{2}},\left(\overline{\mathrm{CO}}_{2}\right)_{\mathrm{p}}$ values and the calculated $\alpha_{\mathrm{p}}$ from Eq. (1) (0.0301, 0.0358 , and $0.0492 \mathrm{~mm} /$ Torr at 38,30 , and $18^{\circ} \mathrm{C}$, respectively):

$$
\mathrm{pH}_{\mathrm{p}}=\mathrm{p} K^{\prime}+\log \left\{\left(\overline{\mathrm{CO}}_{2}\right)_{\mathrm{p}} /\left(\alpha_{\mathrm{p}} \cdot P_{\mathrm{CO}_{2}}\right)\right\} \text {. }
$$

The calculated $\mathrm{p} K^{\prime}$ values are also shown in Table 2 . The $\mathrm{p} K^{\prime}$ was increased with lowering temperature $(T \mathrm{co})$, as expected from the thermodynamical principle. It should be noted that the changes in arterial $\mathrm{pH}_{\mathrm{p}}$ and blood gases of hamsters between 38 and $18^{\circ} \mathrm{C}$ showed a strong resemblance to those of rats between 38 and 
$30^{\circ} \mathrm{C}$ (vide infra).

Table 3 shows the venous $\mathrm{pH}_{\mathrm{p}}$, blood gases, and $\mathrm{Ht}$ recorded at the same $T \mathrm{co}$ as in arterial blood. In rats, the $\mathrm{pH}_{\mathrm{p}}$ in venous blood was significantly decreased between 38 to $30^{\circ} \mathrm{C}(p<0.001)$, but there was no significant difference between 30 and $18^{\circ} \mathrm{C}$. In hamsters, $\mathrm{pH}_{\mathrm{p}}$ produced no considerable difference by cooling to $18^{\circ} \mathrm{C}$ as in the case of arterial blood. The $\mathrm{Pv}_{\mathrm{CO}_{2}}$ in both rats and hamsters showed distinct decreases with loweing $T \mathrm{co}$. The $\left(\overline{\mathrm{CO}}_{2}\right)_{\mathrm{p}}$ and $\mathrm{Ht}$ of venous blood varied with Tco in essentially the same manner as those of arterial blood. The most evident difference between the data in arterial and venous blood was the noticeable reduction of the venous $P_{\mathrm{O}_{2}}$ in both rats and hamsters at $18^{\circ} \mathrm{C}$.

\section{Changes in energy substrates}

Figure 2 shows the changes of blood glucose and liver glycogen contents with $T$ co in rats (A) and hamsters (B). The glucose content did not show a significant difference between arterial and venous blood for both rats and hamsters. Blood glucose of rats at $T$ co of $38^{\circ} \mathrm{C}$ was $120 \mathrm{mg} / \mathrm{dl}$ averaged for arterial and venous blood. In rats, blood glucose level markedly increased from the averaged value

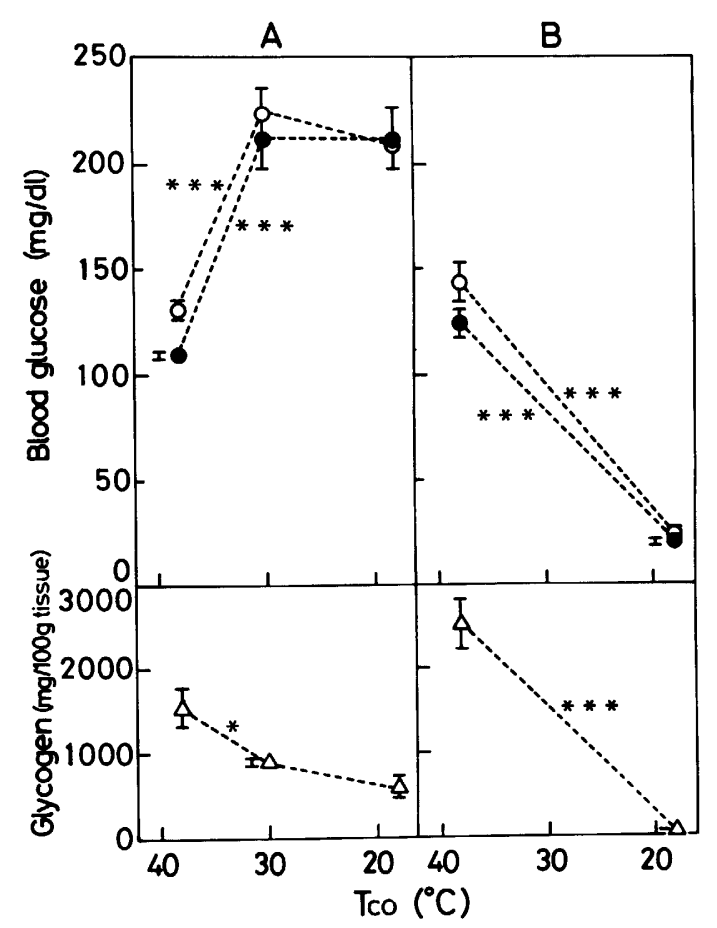

Fig. 2. Plots of the blood glucose (arterial $\bigcirc$; venous $\bullet$ ) and liver glycogen $(\triangle)$ against $T$ co in rats (A) and hamsters (B). ${ }^{*}$ and ${ }^{* * *}$ represent $p<0.05$ and $<0.001$, respectively. 


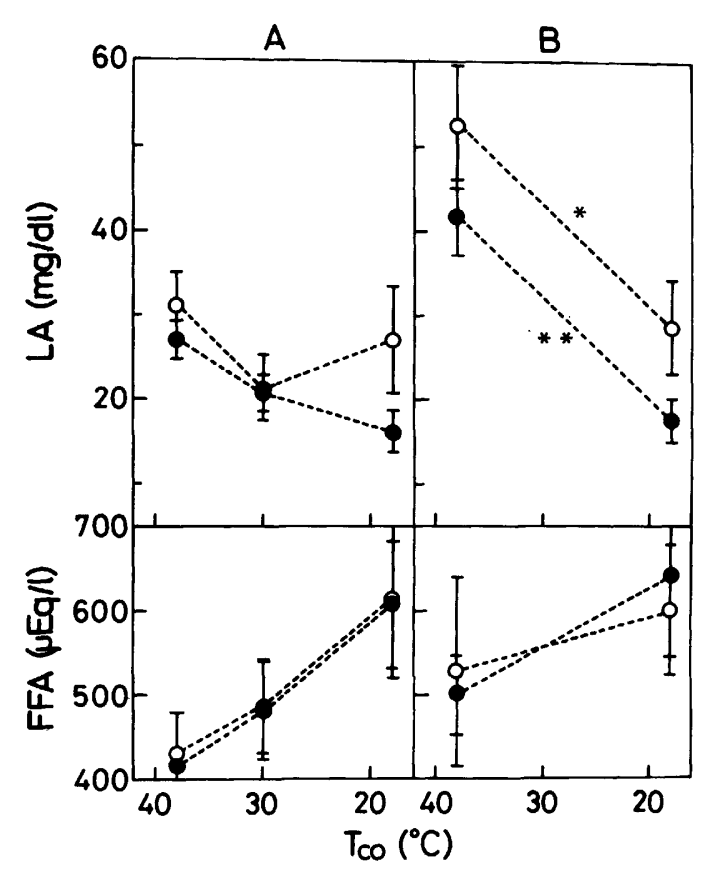

Fig. 3. Plots of the LA and FFA in arterial $(O)$ and venous $(\bullet)$ blood against $T$ co in rats (A) and hamsters (B). * and ${ }^{* *}$ represent $p<0.05$ and $<0.01$, respectively.

at $38^{\circ} \mathrm{C}$ to $217 \mathrm{mg} / \mathrm{dl}$ at $30^{\circ} \mathrm{C}(p<0.001)$ and maintained the high level of $211 \mathrm{mg} /$ $\mathrm{dl}$ at $18^{\circ} \mathrm{C}$. In contrast, blood glucose of hamsters decreased drastically from 134 $\mathrm{mg} / \mathrm{dl}$ at $38^{\circ} \mathrm{C}$ to $20.6 \mathrm{mg} / \mathrm{dl}$ at $18^{\circ} \mathrm{C}(p<0.001)$. The rates of depletion were $84.6 \%$ averaged for the arterial and venous blood. Liver glycogen content in rats showed a slight decrease between 38 and $18^{\circ} \mathrm{C}$. Although the liver glycogen content of hamsters was higher than that of rats at $38^{\circ} \mathrm{C}$, the glycogen was completely exhausted at $18^{\circ} \mathrm{C}(12 \pm 4.1 \mathrm{mg} / 100 \mathrm{~g}$ tissue $)$. The depletion rate was $99.5 \%$.

Figure 3 shows the changes of LA and FFA with Tco in arterial and venous blood of rats (A) and hamsters (B). At $38^{\circ} \mathrm{C}$, LA in hamsters were considerably higher than that in rats for both arterial and venous blood $(p<0.05)$. The high LA levels of hamsters were reduced by a factor of about 2 at $18^{\circ} \mathrm{C}$. The differences in FFA between normo- and hypothermia were not statistically significant in rats as well as in hamsters. However, in both animals FFA tended to increase with lowering Tco.

\section{DISCUSSION}

The present results indicate that rats are less tolerant to cold and more rapidly induced to hypothermia as compared with hamsters. The mechanisms leading to hypothermia and subsequent death may be dependent upon inherent physiological 
characteristics of the animal itself and the temperature at which it is exposed (DoI and Kuroshima, 1979; Kuroshima et al., 1982). It is likely that a combination of restraint and severe cold exposure retarded the appearance of maximum heat production and therefore hypothermia occurred before maximum metabolic performance could be elicited, because the shivering heat production is reduced by the restriction of body movements (SHIMADA and STITT, 1983). However, as mentioned above, the animals in the present study were gently restrained in the Bollman cages. The possibility that the shivering was inhibited by restraint can therefore be excluded. On the other hand, animals used in the present experiments were not cold acclimated, but warm acclimated. Since FFA is the major fuel for shivering thermogenesis in warm-acclimated rats (MASORO, 1966; HrMMS-HAGEN, 1967; Dol et al., 1979), it is inferred from the observed unutilization of FFA (Fig. 3) that the efficient shivering heat production did not occur during hypothermia. The contribution of nonshivering thermogenesis may be less important in the present experiments, because it is well established that in rats and other mammals, the great increase in metabolic response due to nonshivering thermogenesis occurs only after cold acclimation (JANSKÝ, 1973; DOI and KUROSHIMA, 1979). As can be seen in Fig. 1 , the maximum $\dot{V}_{\mathrm{O}_{2}}$ occurred when the $T$ co decreased to approximately $35^{\circ} \mathrm{C}$. This was similar to that reported by ADOLPH (1950) who observed the maximum $\dot{V}_{\mathrm{O}_{2}}$ at Tco of about $35^{\circ} \mathrm{C}$ in his hypothermic rats, and to that by DePocAs et al. (1957) where the highest thermogenesis was obtained at $T$ co near $33^{\circ} \mathrm{C}$ in their $30^{\circ} \mathrm{C}$ acclimated rats exposed to $-15^{\circ} \mathrm{C}$. The occurrence of the peak thermogenesis at Tco of around $35^{\circ} \mathrm{C}$ may be interpreted by the imbalance between the two timedependent rates, namely, heat production and heat loss. Since the increase in heat loss occurs immediately after exposure to cold, while the increase in heat production takes time to reach its peak level, the imbalance would result in a continuous and steady decline of $T$ co until $18^{\circ} \mathrm{C}$. Although we have not directly measured heat loss, it is reasonable to assume that the heat loss surpassed the heat production.

It could be argued that the $\mathrm{CO}_{2}$ concentration in the metabolic box may affect the occurrence of acidosis and the subsequent change in Tco. STUPFEL (1974) reported that when rats were exposed to cold, the decline of Tco was significantly greater in a hypercapnic condition of above $10 \% \mathrm{CO}_{2}$ than in a normal atmosphere, and the effects of $\mathrm{CO}_{2}$ on Tco was not significant at around $3 \% \mathrm{CO}_{2}$. Therefore, this possibility appears unlikely, because the $\mathrm{CO}_{2}$ concentration in the box was at most $1-3 \%$. In fact, as shown in Tables 2 and 3, the accumulation of $\mathrm{CO}_{2}$ was not observed for rats as well as hamsters. The question remaines as to the cause(s) of acidosis in rats. Although the impaired functions of the respiratory center and/or the respiratory muscles seem to be involved in the respiratory acidosis, further studies should help to establish the mechanisms of the respiratory acidosis during hypothermia.

Figure 4 shows $\mathrm{pH}-\left(\overline{\mathrm{CO}}_{2}\right)_{\mathrm{p}}$ diagrams at $\mathrm{Tco}$ of 38,30 , and $18^{\circ} \mathrm{C}$ for arterial blood of rats and hamsters. The observed bound $\mathrm{CO}_{2}$ concentration, $\left(\overline{\mathrm{CO}}_{2}\right)_{\mathrm{p}}$ 


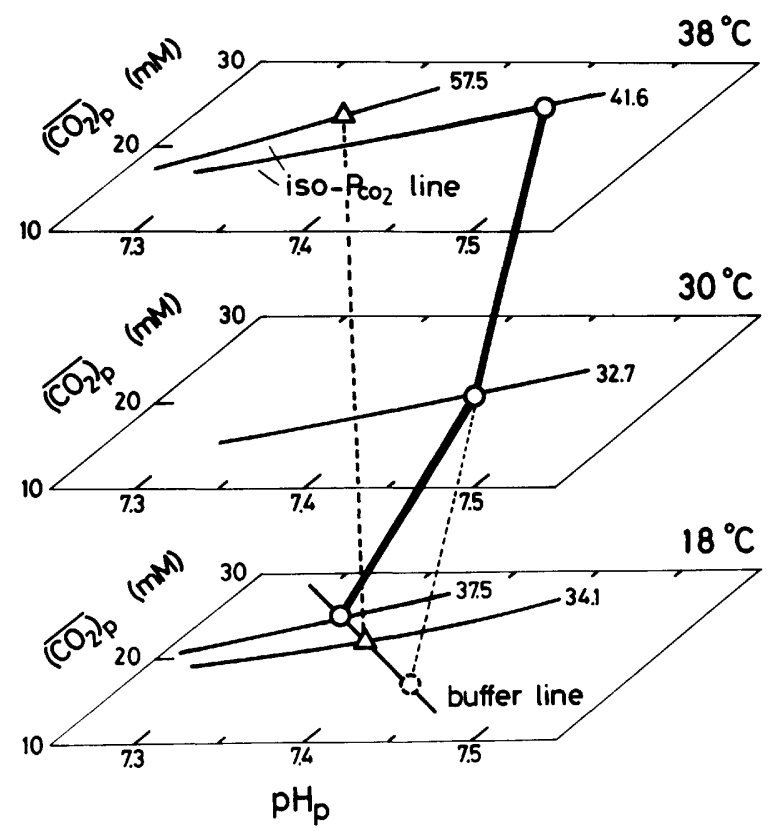

Fig. 4. $\mathrm{pH}_{\mathrm{p}}-\left(\overline{\mathrm{CO}_{2}}\right)_{\mathrm{p}}$ diagrams of arterial blood of rats and hamsters at $T \mathrm{co}$ of 38, 30, and $18^{\circ} \mathrm{C}$. The circular and triangular points represent the observed mean $\mathrm{pH}_{\mathrm{p}}, P_{\mathrm{CO}_{2}}$, and $\left(\overline{\mathrm{CO}_{2}}\right)_{\mathrm{p}}$ values for rats and hamsters, respectively. See text for details.

consists of bicarbonate $\left(\mathrm{HCO}_{3}^{-}\right)$and carbamate $\left(\mathrm{R}-\mathrm{NHCOO}^{-}\right)$concentrations, where $\mathrm{R}$ denotes the amino acid residues of hemoglobin. Since the major part of bound $\mathrm{CO}_{2}$ in blood under physiological conditions is $\mathrm{HCO}_{3}{ }^{-}$, Fig. 4 can be regarded as the $\mathrm{pH}$-bicarbonate diagram. The circular and triangular points in the figure represent the mean $\mathrm{pH}_{\mathrm{p}}, \mathrm{Pa}_{\mathrm{CO}_{2}}$, and $\left(\overline{\mathrm{CO}}_{2}\right)_{\mathrm{p}}$ values shown in Table 2 . The $\left(\overline{\mathrm{CO}}_{2}\right)_{\mathrm{p}}$ on the iso- $\mathrm{P}_{\mathrm{CO}_{2}}$ lines were calculated from Eq. (2) by changing the $\mathrm{pH}_{\mathrm{p}}$ with the fixed $\mathrm{Pa}_{\mathrm{CO}_{2}}, \mathrm{p} K^{\prime}$, and $\alpha_{\mathrm{p}}$ values at each temperature. As shown in Table 2, the arterial $\mathrm{pH}_{\mathrm{p}}$ of rats at $T \mathrm{co}$ of $18^{\circ} \mathrm{C}$ was lower than the control $\mathrm{pH}_{\mathrm{p}}$ value at $38^{\circ} \mathrm{C}$ by $0.126 \mathrm{pH}$ unit, indicating that rats suffered acidosis at $18^{\circ} \mathrm{C}$. Since the decrease in $\mathrm{pH}_{\mathrm{p}}$ was accompanied by the increase in $\left(\overline{\mathrm{CO}}_{2}\right)_{\mathrm{p}}$, the acidosis is not characteristic of the metabolic acidosis, but the respiratory acidosis. The increased $\mathrm{Pa}_{\mathrm{CO}_{2}}$ (statistically non-significant) and unchanged LA level also indicated the respiratory acidosis. At $T$ co of $30^{\circ} \mathrm{C}$, rats could maintain the normal arterial $\mathrm{pH}_{\mathrm{p}}$ by their highventilation efforts. The hyperventilation was manifested by the observed decrease in $\mathrm{Pa}_{\mathrm{CO}_{2}}$ and high $\mathrm{Pa}_{\mathrm{O}_{2}}$ level at $30^{\circ} \mathrm{C}$. If rats could maintain the homeostasis even at $18^{\circ} \mathrm{C}$ as hamsters could, the point representing the acid-base balance should be the circle shown with a broken line in Fig. 4 . In the actual case at $18^{\circ} \mathrm{C}, \mathrm{pH}_{\mathrm{p}}$ of rats decreased and $\left(\overline{\mathrm{CO}}_{2}\right)_{\mathrm{p}}$ increased along a supposed buffer line, accompanying the increase in $\mathrm{Pa}_{\mathrm{CO}_{2}}$. The decrease in $\mathrm{pH}$ and increases in both $\mathrm{HCO}_{3}{ }^{-}$and $\mathrm{Pa}_{\mathrm{CO}_{2}}$ 
along the buffer line is characterized by the uncompensated respiratory acidosis caused by hypoventilation (DAVENPORT, 1974). The decrease in $\mathrm{pH}_{\mathrm{p}}$ in vivo should be moderated by the renal compensation. The above discussion is not decisive because of the uncertainty on the buffer line at $18^{\circ} \mathrm{C}$, but presumably the respiratory acidosis is an important factor for the observed decrease in $\mathrm{pH}_{\mathrm{p}}$ of the hypothermic rats.

VOLKERT and MusacCHIA (1970) reported that the decreases in arterial $\mathrm{pH}_{\mathrm{p}}$ and $\mathrm{Pa}_{\mathrm{O}_{2}}$ and the increase in $\mathrm{Pa}_{\mathrm{CO}_{2}}$ were observed in hamsters at $T \mathrm{co}$ of $6^{\circ} \mathrm{C}$. Therefore, the failure in respiratory functions observed for rats at $18^{\circ} \mathrm{C}$ is thought to equally occur in hamsters in deep hypothermia at $6^{\circ} \mathrm{C}$. It should be noted in this connection that the changes in the arterial $\mathrm{pH}_{\mathrm{p}}$. and blood gases of hamsters between 38 and $18^{\circ} \mathrm{C}$ resembled those of rats between 38 and $30^{\circ} \mathrm{C}$. From such observations, we have a hypothesis that the $\mathrm{pH}_{\mathrm{p}}$ and blood gases of hamsters change with $T$ co in the same way as those of rats except for the temperature difference of $12^{\circ} \mathrm{C}$. In other words, if we introduce a concept of effective body temperature ( $T$ eff) which characterizes the tolerance to cold, the Teff of hamsters is higher than that of rats by $12^{\circ} \mathrm{C}$. Deducing this hypothesis to normothermia, we obtain the $T$ eff of normothermic hamsters as $50(38+12)^{\circ} \mathrm{C}$. Such a high body temperature is of course unnatural, but this effectively high body temperature is consistent with the observed high $\mathrm{Pa}_{\mathrm{CO}_{2}}$ in normothermic hamsters (57.5 Torr); the $P_{\mathrm{CO}_{2}}$ at $50^{\circ} \mathrm{C}$ is calculated to be 68.9 Torr from the normal $P_{\mathrm{CO}_{2}}$ at $38^{\circ} \mathrm{C}$ observe in rats $(41.6 \mathrm{Torr}$ ) by multiplying the temperature coefficient of SEVERINGHaus (1964). The high Teff of hamsters possibly indicates the latent power to survive the hypothermia during hibernation. The high $\mathrm{Pa}_{\mathrm{CO}_{2}}$ of hamsters at $T \mathrm{co}$ of $38^{\circ} \mathrm{C}$ was also shown by LYMAN and Hastings (1951) and Volkert and Musacchia (1970). Volkert and MusaCCHIA (1970) pointed out that the high $\mathrm{Pa}_{\mathrm{CO}_{2}}, 56.0$ Torr was lowered to 50.4 Torr if the blood was sampled without anesthesia of Nembutal. In our experiments, a light anesthesia with ether was used for blood samplings. Although some effects of anesthesia may be included in our high $\mathrm{Pa}_{\mathrm{CO}_{2}}$ of hamsters, it is evident that $\mathrm{Pa}_{\mathrm{CO}_{2}}$ at $38^{\circ} \mathrm{C}$ of hamsters is much higher than that of rats. The $\mathrm{Pa}_{\mathrm{CO}_{2}}$ in normothermic ground squirrel (a hibernator) was reported to be 42 Torr by KENT and PEIRCE II (1967). It would be interesting to investigate whether the extremely high $\mathrm{Pa}_{\mathrm{CO}_{2}}$ in normothermia is specific to hamsters or common to hibernators.

As shown in Fig. 2 the blood glucose of rats significantly increased during the early phase of hypothermia. This observation is in accord with those of FuHRMAN and CRismon (1947) and Popovic (1960). The former authors found that the increase in blood glucose was observed only for fed rats. The rats used in the present work had been fed before experiments. Hypercapnic hypoxia was suggested to be responsible for the hyperglycemia in rats (POPOVIC, 1960), but neither hypercapnia nor hypoxia was observed in the present work for rats at $\mathrm{Tco}$ of $30^{\circ} \mathrm{C}\left(\mathrm{Pa}_{\mathrm{CO}_{2}}\right.$ and $\mathrm{Pa}_{\mathrm{O}_{2}}$ in Table 2). In contrast to rats, the almost complete depletion of blood glucose was observed for hamsters at $T$ co of $18^{\circ} \mathrm{C}$ (Fig. 2). The observed distinct contrast in the glucose utilization between rats and hamsters may be interpreted as due to the 
difference in the oxygen uptake at the mitochondria level. It seems likely that the insufficient supply of stable metabolic substrates at the tissue level is also one of the prime causes for the observed decrease in Tco. From the observations of exhaustion of blood glucose in hamsters as well as the unutilization in rats at $T$ co of $18^{\circ} \mathrm{C}$, it is postulated that the glucose availability is one of the rate-limiting factors for the survival in hypothermia. In addition, the energy stores dissipated during the long induction period in cold for hamsters might be severe enough to limit further hypothermic viability. Under these conditions, the liver glycogen contents in hamsters were depleted to approximately zero. It was found for hamsters that the longer the induction time to hypothermia at $T$ co of $18^{\circ} \mathrm{C}$, the more blood glucose and liver glycogen were consumed. Furthermore, as expected from the parallel decrease between blood glucose and liver glycogen of hamsters (Fig. 2), the amount of blood glucose showed a fairly good correlation with that of liver glycogen measured in the identical hamster $(n=9)$ :

$$
\begin{array}{r}
\text { Blood glucose }(\mathrm{mg} / \mathrm{dl})=26.4+0.0559 \cdot \text { Liver glycogen }(\mathrm{mg} / 100 \mathrm{~g} \text { tissue }) \\
(r=0.882, \quad p<0.01) .
\end{array}
$$

The rates of mobilization of metabolic fuels may be less efficient in the rats than in the hamsters during hypothermia at the same Tco. The induction of hypothermia is associated with marked metabolic alterations in energy substrates. This could possibly be due to effects of impairment of utilization of metabolic fuels incurred during the induction phase where exhaustive efforts were made by the animals to avoid the onset and progression of hypothermia.

This study was supported in part by Grant-in-Aid for Scientific Research from the Ministry of Education, Science and Culture of Japan (60570075).

\section{REFERENCES}

AdOLPH, E. F. (1950) Oxygen consumptions of hypothermic rats and acclimatization to cold. Am. J. Physiol., 161: 359-373.

Anderson, G. L., Volkert, W. A., and Musacchia, X. J. (1971) $\mathrm{O}_{2}$ consumption, electrocardiogram, and spontaneous respiration of hypothermic hamsters. Am. J. Physiol., 221: 1774-1778.

Barker, S. B. and Summerson, W. H. (1941) The colorimetric determination of lactic acid in biological material. J. Biol. Chem., 138: 535-554.

Bollman, J. L. (1948) A cage which limits the activity of rats. J. Lab. Clin. Med., 33: 1348.

Carroll, N. V., Longley, R. W., and Roe, J. H. (1956) The determination of glycogen in liver and muscle by use of anthrone reagent. J. Biol. Chem., 220: 583-593.

DavenPort, H. W. (1974) The ABC of Acid-Base Chemistry, The Univ. of Chicago Press, Chicago, pp. $47-103$.

DePocAs, F. (1962) Body glucose as fuel in white rats exposed to cold: Results with fasted rats. Am. J. Physiol., 202: 1015-1018.

DEPOCAS, F., HART, J. S., and HérouX, O. (1957) Energy metabolism of the white rat after 
acclimation to warm and cold environments. J. Appl. Physiol., 10: 393-397.

Doi, K. and Kuroshima, A. (1979) Lasting effect of infantile cold experience on cold tolerance in adult rats. Jpn. J. Physiol., 29: 139-150.

Doi, K., Ohno, T., Kurahashi, M., and Kuroshima, A. (1979) Thermoregulatory nonshivering thermogenesis in men, with special reference to lipid metabolism. Jpn. J. Physiol., 29: 359-372.

Fuhrman, F. A. and Crismon, J. M. (1947) The influence of acute hypothermia on the rate of oxygen consumption and glycogen content of the liver and on the blood glucose. Am. J. Physiol., 149: 552-560.

Himms-Hagen, J. (1967) Sympathetic regulation of metabolism. Pharmacol. Rev., 19: $367-461$.

ITAYA, K. and UI, M. (1965) Colorimetric determination of free fatty acids in biological fluids. J. Lipid Res., 6: 16-20.

JANSKÝ, L. (1973) Non-shivering thermogenesis and its thermoregulatory significance. Biol. Rev., 48: 85-132.

Kent, K. M. and PeiRCe II, E. C. (1967) Acid-base characteristics of hibernating animals. J. Appl. Physiol., 23: 336-340.

Kuroshima, A., Yahata, T., DoI, K., and Ohno, T. (1982) Thermal and metabolic responses of temperature-acclimated rats during cold and heat exposures. Jpn. J. Physiol., 32: 561-571.

Lyman, C. P. and Hastings, A. B. (1951) Total $\mathrm{CO}_{2}$, plasma pH and $P_{\mathrm{CO}_{2}}$ of hamsters and ground squirrels during hibernation. Am. J. Physiol., 167: 633-637.

Masoro, E. J. (1966) Effect of cold on metabolic use of lipids. Physiol. Rev., 46: 67-101.

McGovern, J. J., Jones, A. R., and SteinberG, A. G. (1955) The hematocrit of capillary blood. New Eng. J. Med., 253: 308-312.

MusacChia, X. J. and JACOBS, M. (1973) Helium-cold induced hypothermia in the white rat. Proc. Soc. Exp. Biol. Med., 142: 734-739.

NATELSON, S. (1951) Routine use of ultramicro methods in the clinical laboratory. Am. J. Clin. Pathol., 21: 1153-1172.

Popovic, V. (1960) Physiological characteristics of rats and ground squirrels during prolonged lethargic hypothermia. Am. J. Physiol., 199: 467-471.

Prewitt, R. L., Anderson, G. L., and Musacchia, X. J. (1972) Evidence for a metabolic limitation of survival in hypothermic hamsters. Proc. Soc. Exp. Biol. Med., 140: 1279-1283.

RaHN, H., ReEves, R. B., and Howell, B. J. (1975) Hydrogen ion regulation, temperature, and evolution. Am. Rev. Respir. Dis., 112: 165-172.

Roe, J. H. (1955) The determination of sugar in blood and spinal fluid with anthrone reagent. J. Biol. Chem., 212: 335-343.

Rosenthal, T. B. (1948) The effect of temperature on the $\mathrm{pH}$ of blood and plasma in vitro. J. Biol. Chem., 173: 25-30.

Severinghaus, J. W. (1964) Blood gas concentrations. In: Handbook of Physiology, Section 3, Respiration, ed. by Fenn, W. O. and Rahn, H., The American Physiological Society, Washington, D. C., Vol. I, pp. 1475-1487.

Shimada, S. G. and StitT, J. T. (1983) Inhibition of shivering during restraint hypothermia. Can. J. Physiol. Pharmacol., 61: 977-982.

SiggaARD-ANDERSEN, O. (1962) The first dissociation exponent of carbonic acid as a function of $\mathrm{pH}$. Scand. J. Clin. Lab. Invest., 14: 587-597.

Stupfel, M. (1974) Carbon dioxide and temperature regulation of homeothermic mam- 
mals. In: Carbon Dioxide and Metabolic Regulations, ed. by NAHAS, G. and SCHAEFER, K. E., Springer-Verlag, New York, pp. 163-186.

VolKert, W. A. and MusaCCHIA, X. J. (1970) Blood gases in hamsters during hypothermia by exposure to $\mathrm{He}-\mathrm{O}_{2}$ mixture and cold. Am. J. Physiol., 219: 919-922.

WaNG, L. C. H. (1978) Factors limiting maximum cold-induced heat production. Life Sci., 23: 2089-2098.

WANG, L. C. H. and Peter, R. E. (1977) Changes in plaşma glucose, FFA, corticosterone, and thyroxine in $\mathrm{He}_{2} \mathrm{O}_{2}$-induced hypothermia. J. Appl. Physiol., 42: 694-698. 